\title{
Research Abstract
}

\section{Epidemiological Aspects of Ascariasis and Associated Risk Factors Among Primary School Children In Lambata Community Niger State, Nigeria During 2019-2020}

\section{Okoroiwu, Gideon I.A.}

Dept of Public Health Science Faculty of Health Sciences Nat. Open University of Nigeria Abuja, Nigeria.

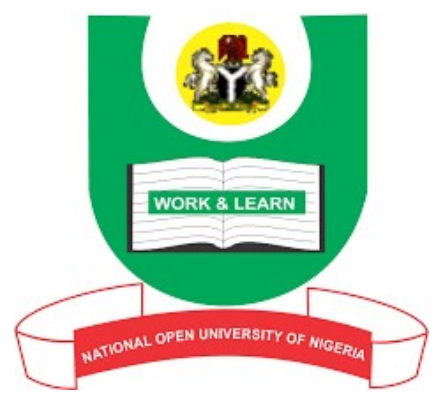

E-mail

okoroiwugia@yahoo.com

Phone

$+2348036677539$

Author's ORCID ID

https://orcid.org/0000-

00027206-6397

\begin{abstract}
Ascaris worm as one of the commonest helminthic infection constitutes a major public health challenge and concern in the majority of developing countries. This study was conducted to assess the prevalence of Ascaris worm infection and its associated risk factors among primary school children in Lambata community, to determine the prevalence of Ascaris infection, age, gender and associated risk factors among them to create awareness and effective management program. A cross-sectional descriptive study was adopted. This study was conducted between January 2019 and November 2020, in nine selected primary schools in Lambata community. A total of 303 stool samples were collected using random sampling to determine the prevalence of Ascaris infection using stool smear technique. The socio-demographic data was collected using a structured interview questionnaire. The collected data were analyzed using simple percentages, OR and chi-square analytical methods. Out of the 303 screened stools, 156 (51.5\%) of them had Ascaris infection. The most infected age-groups were 1112 years old $(73.8 \%$; OR $=2.11)$; followed by $9-10$ years $(57.1 \%$; OR $=2.01)$, while $6-8$ years old had the lowest rate $(42.3 \%$; $\mathrm{OR}=1.00)$ of infection. Males $(65.9 \%$; $\mathrm{OR}=2.00)$ were more infected than their female $(39.9 \%$; OR $=0.09)$ counterparts $(P<0.05)$. Age, educational status / occupational status of parents of the children, and defecation habits were significantly $(P<0.05)$ associated with the prevalence of Ascaris infection. With the overall prevalence of $51.5 \%$ of Ascaris infection among the children, there is an indispensable need for health education promotion and coordinated de-worming of the primary school children in this community
\end{abstract}

Keywords: Epidemiology, Ascaris, Stool, Health, Helminth, Children, Promotion, Education

Proceedings Reference Format

Okoroiwu, G.I.A (2021): Epidemiological Aspects of Ascariasis and Associated Risk Factors Among Primary School Children In Lambata Community, Niger State, Nigeria During 2019-2020. Proceedings of the 28th iSTEAMS Intertertiary Multidisciplinary Conference. American International University West Africa, The Gambia. October, 2021. Pp 158 www.isteams.net/gambia2021. DOI - https://doi.org/ 10.22624/AIMS/iSTEAMS-2021/V28P12x 